\title{
A pilot study to investigate and analyse script components of hospitalised individuals in Ukraine diagnosed with schizophrenia paranoid sub-type
}

\author{
(C) 2014 Ganna Golovan
}

\begin{abstract}
Based on World Health Organisation (2014a) identification a lack of psychosocial interventions for the c. 24 million people worldwide suffering from schizophrenia, and a corresponding paucity of relevant transactional analysis literature, the author went on to conduct a pilot study of 27 participants in Ukraine, who were hospitalised and diagnosed by psychiatrists as schizophrenia paranoid sub-type. Four questionnaires were used in Russian: Internal Ego States Questionnaire (Hay, 1996), Driver Questionnaire (Cox, 2001), Critical Points of Development Questionnaire (Gusakovski, 2000 based on Bradshaw, 1991) and Brief Script Questionnaire (Stewart, 1999), the latter accompanied by a clinical interview during which diagnoses of other TA elements were made. Limitations in terms of un-validated questionnaires and statistical validity are noted but the study is presented, and copies of the questionnaires in English are published with the permission of the authors, in order to encourage further research into this hitherto neglected area.
\end{abstract}

Keywords: transactional analysis, schizophrenia paranoid sub-type, script, ego state, personality adaptation, drivers, life positions, doors to therapy, questionnaires

\section{Literature Review}

According to the World Health Organization (2014a) schizophrenia is a severe form of mental illness affecting about 24 million people worldwide, mostly in the age group 15-35 years, and in spite of there being effective pharmacological and psychosocial interventions, more than $50 \%$ of persons with schizophrenia are not receiving appropriate care. They provide 30 pages of references of papers on the subject (World Health Organization 2014b).

Mari and Steiner (1998) conducted a rigorous methodological meta-analysis of 12 randomised placebo-controlled researches to determine the effectiveness of family therapy and found that the recurrence rate is reduced compared with the recurrence rate of patients who did not receive psychotherapy.

Based on meta-analysis of researches (Garety et al, 1994; Tarrier et al, 1993; Tarrier et al, 1998; Drury, 1996; Hogarty, 1997) devoted to studying the efficacy of cognitive-behavioural therapy, Birchwood and Spencer (1999) found that cognitive-behavioural therapy caused a statistically significant reduction of psychotic symptoms compared with a control group.

Although Bellack et al (1984), Liberman at al (1998) and Hogarty at al (1986) claimed that, considering the lack of social adaptation of patients with schizophrenia, social skills training improves their functioning, Birchwood \& Spencer, (1999) determined that reducing the frequency of relapse was temporary and insignificant.

Transactional Analysis Literature

Schiff, Erb, Warner, Kline, Bowman \& Schiff (1977) reported on the effectiveness of transactional analysis and reparenting at the level of biochemical changes (normalization of tryptophan uptake) while working with patients they had diagnosed as having process schizophrenia and who took no medication during the study. However, the authors do not describe the treatment, say only that they used Minnesota Multiphasic Personality Inventory schizophrenic scale (SC\#8) (University of Minnesota, 1943 [ref added; does not appear in original article] for diagnosis, acknowledge that diagnosis according to DSM III (American Psychiatric Association 1980) might have been different, and had samples of 20 and 5 only. The Schiff et al (1977) study was based on work by Berlet et al (1964); similar studies on antioxidants continue to be conducted - see Akyol et al (2002), Ben Othmen at al (2008). 
Wilson, White \& Heiber (1985) reported on the effectiveness of the reparenting method when dealing with schizophrenia used in a hospital setting. They comment on how they were impressed with the work of Schiff (1970) and therefore adopted some of these techniques. However, they also wrote that they "borrow freely from object relations theory ... ([and] some of the concepts of [several well-known non-TA practitioners]." (p. 211)

White (1999) commented on the "gaping hole [within the transactional analysis literature] in the theory and practice of the treatment of most schizophrenics; there is no theory and practice of treating psychoses that does not involve residential treatment." (p. 133) $\mathrm{He}$ went on to call for "the construction of a transactional analysis approach to schizophrenia that is accessible to the majority of those who suffer from this disorder." (p. 137) and, within his paper, to propose a form of no-psychosis contract that might contribute to this.

Finally, as this paper was being prepared for publication, Mellacqua (2014) has proposed that schizophrenia is a relational trauma disorder rather than the result of symbiosis, intrapsychic conflicts or complex contaminations. Mellacqua provides a helpful review of the historical perspectives concerning the psychiatrist definition of schizophrenia, points out how the Schiff (1975) material does not adequately take into account various characteristics of schizophrenic pathology, and presents case examples to support a conclusion that schizophrenics are "individuals whose psychobiography is marked by premature and often enduring traumatic relational experiences with significant others (e.g. parents or other figures acting in loco parentis) that lead to the most pervasive fragmentation of the self." (p. 24)

\section{Research Objectives}

This study began with the expectation that it would lead to identification of TA concepts associated with schizophrenia. However, as the results were reviewed, the limitations described below were identified, and the outcome was changed to the publication of a methodology that might stimulate further research.

To assist in this, permission was granted by the copyright holders of the original questionnaires so they could be reproduced here in full as Appendices.

\section{Ethical Considerations}

The contract with the medical staff and patients included that all patients could give their agreement or disagreement to take part in this research. Before being asked for their decision, they were informed about the goals, structure and methods of the research. All participants were responsible for themselves; they were aware who were they, where were they, and what was happening. They knew they had psychological problems. From the legal point of view they were Sui Juris i.e. they had the capacity to manage their own affairs and were not under legal disability to act for themself.

All participants as well as medical staff were informed that they would not be provided with any results. Also all parties agreed that results would be published in foreign journal(s) without mention of any names. The researcher would keep all results in a safe place (working office) outside hospital; all papers were coded so that there were no names or other signs on papers which could be recognised as belonging to a specific person.

Through this contract we aimed to contribute to ethical research practice. We protected the boundaries of all parties, and especially the boundaries of participants. We were aware about their right to refuse and we discussed it with each of them. Before including each participant we checked their competence through documents and through the making of the contract from Adult ego state. It is important to keep in mind that all participants were in remission phase and had no intellectual damage.

These ethical aspects were discussed at supervisions with a Teaching \& Supervising Transactional Analyst (Psychotherapy) to avoid discounting concerning ethics. Also, to protect participants we engaged in supervisions with a psychiatrist outside the hospital to stay aware about medical aspects.

\section{Methodology}

Four questionnaires, with one as the basis for clinical interview, were used for an empirical investigation:

- Internal Ego State Questionnaire (Hay, 1996) included as Appendix 1

- Driver questionnaire (Cox, 2001) unpublished, included as Appendix 2

- Critical Points of Development questionnaire (Gusakovski, 2000) unpublished, included as Appendix 3

- Brief Script Questionnaire (Stewart, 1999) included as Appendix 4

The Cox and Gusakovski questionnaires had been made available in Russian and were used in that language; the Hay and Stewart material was translated and had been used at various workshops prior to this study.

The Gusakovski questionnaire was based on material by Bradshaw (1991) that was taught in Russia by Patricia J Cox. 
These questionnaires were selected to reflect behavioural aspects (Driver questionnaire), structural aspects (Internal ego state questionnaire and Critical Points of Development questionnaire) and both behavioural and structural aspects (Brief Script Questionnaire).

As discussed under Limitations, these questionnaires have not been validated; however, they were chosen because of their links to transactional analysis concepts.

Whilst using the Brief Script Questionnaire, the researcher also conducted clinical interviews, so that the time spent with each subject ranged from 2.5 to 4 hours. Knowledge of all 4 types of diagnosis social, historical, behavioural and phenomenological (Berne, 1966) and the diagnostic criteria e.g. pose, typical gestures, characteristic words, typical intonation etc. (Joines \& Stewart 1987) were used to identify probable functional ego states, existential life positions, and open doors to therapy (Ware 1983). Childhood strokes were also explored.

\section{Subjects}

The study involved 27 patients diagnosed by psychiatrists as suffering from the paranoid form of schizophrenia in remission, aged 20 to 40 years, without the apathy-dissociative defect. All studied gave their consent to participate. The distribution of patients by gender was approximately equal. All patients at the time of the study were receiving antipsychotic medications (e.g. olanzapine, haloperidol, risperidone, seroquel, etc.).

\section{Results}

Internal Ego State Questionnaire

The scores for these are shown in Table 1. On inspection, it can be seen that some individuals scored fairly evenly across the three scales. We therefore identified those where one of the scores was 2 or more points below the next highest score. These are shaded in the Table to indicate where this difference occurred for the highest score and where it occurred for the lowest score. Table 2 summarises these results. It can be seen that there are very few highest scores for Internal Child compared to Internal Parent and Internal Adult, each of which are at approximately the same level. For the lowest scores, the difference is much more distinct, with Internal Parent and Internal Adult again being at similar levels but now very few, and with Internal Child showing clearly as a lower score for 12 of the participants.

Driver Questionnaire

Table 3 shows the results of the driver questionnaire. The questionnaire contains five questions per driver so the maximum score for any driver is 5 . As with the Internal Ego State Questionnaire, some participants showed a narrow range of scores so it is not possible to state with any certainty that they have a dominant driver. However, we have assumed that there is more significance when the highest or lowest score is two or more points different from the next highest or lowest score. There are only four participants where the highest score meets this criterion: two of these have Please Other as dominant, one has Be Perfect and one has Hurry Up. For the least scored driver where there is a difference of at least two marks, there are again only five: three for Hurry Up and two for Try Hard.

\begin{tabular}{|c|c|c|c|}
\hline & $\begin{array}{c}\text { Internal } \\
\text { Parent } \\
\end{array}$ & $\begin{array}{c}\text { Internal } \\
\text { Adult }\end{array}$ & $\begin{array}{c}\text { Internal } \\
\text { Child }\end{array}$ \\
\hline 1 & 14 & 12 & 13 \\
\hline 2 & 14 & 15 & 11 \\
\hline 3 & 16 & 15 & 5 \\
\hline 4 & 9 & 9 & 5 \\
\hline 5 & 13 & 11 & 5 \\
\hline 6 & 12 & 12 & 12 \\
\hline 7 & 13 & 17 & 12 \\
\hline 8 & 13 & 12 & 11 \\
\hline 9 & 13 & 14 & 14 \\
\hline 10 & 7 & 13 & 9 \\
\hline 11 & 11 & 11 & 11 \\
\hline 12 & 15 & 17 & 14 \\
\hline 13 & 14 & 11 & 16 \\
\hline 14 & 14 & 15 & 10 \\
\hline 15 & 5 & 11 & 7 \\
\hline 16 & 11 & 16 & 4 \\
\hline 17 & 5 & 6 & 12 \\
\hline 18 & 15 & 15 & 7 \\
\hline 19 & 14 & 10 & 4 \\
\hline 20 & 19 & 15 & 15 \\
\hline 21 & 10 & 15 & 13 \\
\hline 22 & 13 & 15 & 11 \\
\hline 23 & 16 & 14 & 10 \\
\hline 24 & 15 & 11 & 11 \\
\hline 25 & 6 & 20 & 4 \\
\hline 26 & 14 & 14 & 11 \\
\hline 27 & 13 & 10 & 2 \\
\hline
\end{tabular}

Table 1: Results of Internal Ego-State Questionnaire (Hay 1996) 


\begin{tabular}{lccc}
\hline & $\begin{array}{c}\text { Internal } \\
\text { Parent }\end{array}$ & $\begin{array}{c}\text { Internal } \\
\text { Adult }\end{array}$ & $\begin{array}{c}\text { Internal } \\
\text { Child }\end{array}$ \\
\hline $\begin{array}{l}\text { Number of } \\
\text { highest scores }\end{array}$ & 6 & 8 & 2 \\
\hline $\begin{array}{l}\text { Number of } \\
\text { lowest scores }\end{array}$ & 3 & 1 & 12 \\
\hline
\end{tabular}

Table 2: Highest and lowest scores on Internal EgoState Questionnaire (Hay 1996)

\begin{tabular}{|c|c|c|c|c|c|}
\hline & 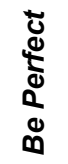 & $\begin{array}{l}0 \\
\vdots \\
\vdots \\
\infty \\
0 \\
0\end{array}$ & 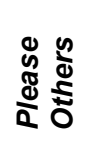 & \begin{tabular}{l}
$\frac{2}{5}$ \\
\multirow{2}{1}{}
\end{tabular} & $\begin{array}{l}\frac{1}{2} \\
\frac{\pi}{2} \\
\frac{1}{2}\end{array}$ \\
\hline 1 & 2 & 4 & 3 & 1.5 & 3 \\
\hline 2 & 2.5 & 2.5 & 4 & 3 & 1.5 \\
\hline 3 & 4 & 5 & 4 & 4 & 4 \\
\hline 4 & 3 & 3 & 2 & 3 & 1 \\
\hline 5 & 4 & 4 & 3 & 1 & 1 \\
\hline 6 & 3 & 3.5 & 4.5 & 0.5 & 2.5 \\
\hline 7 & 1 & 2.5 & 4.5 & 2 & 1.5 \\
\hline 8 & 3 & 1.5 & 3.5 & 2 & 4.5 \\
\hline 9 & 4 & 4.5 & 5 & 2 & 2 \\
\hline 10 & 1.5 & 3 & 3.5 & 1.5 & 3 \\
\hline 11 & 2 & 2 & 3 & 0 & 0 \\
\hline 12 & 3 & 3 & 3 & 0 & 1 \\
\hline 13 & 3 & 3.5 & 4.5 & 4 & 3.5 \\
\hline 14 & 4 & 4 & 4 & 4 & 2 \\
\hline 15 & 2 & 3 & 3 & 1 & 4 \\
\hline 16 & 1 & 4 & 4 & 2.5 & 2 \\
\hline 17 & 2 & 2 & 3.5 & 1 & 4 \\
\hline 18 & 4 & 3.5 & 3.5 & 1.5 & 3.5 \\
\hline 19 & 3 & 5 & 4 & 2 & 3 \\
\hline 20 & 3 & 4 & 4 & 3.5 & 1 \\
\hline 21 & 2.5 & 4 & 2.5 & 1 & 3.5 \\
\hline 22 & 4 & 4.5 & 5 & 2 & 4 \\
\hline 23 & 5 & 3 & 2 & 1.5 & 0.5 \\
\hline 24 & 4 & 4 & 4.5 & 3 & 2.5 \\
\hline 25 & 1 & 2 & 1 & 4 & 1 \\
\hline 26 & 3.5 & 2.5 & 4 & 2.5 & 3.5 \\
\hline 27 & 0 & 2 & 5 & 1 & 1 \\
\hline $\begin{array}{l}\frac{n}{\frac{1}{5}} \\
\frac{1}{6}\end{array}$ & 75 & 90.5 & 97.5 & 56 & 62 \\
\hline
\end{tabular}

$\overline{\text { Table 3: Results of Driver Questionnaire (Cox 2001) }}$

\begin{tabular}{|c|c|c|c|c|c|}
\hline & $\begin{array}{l}n \\
\underline{E} \\
\vdots \\
\vdots \\
\vdots \\
0 \\
0\end{array}$ & 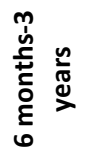 & 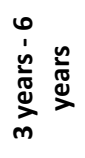 & 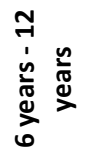 & 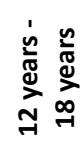 \\
\hline 1 & 4 & 5 & 4 & 10 & 3 \\
\hline 2 & 2 & 3 & 3 & 2 & 2 \\
\hline 3 & 6 & 3 & 4 & 4 & 4 \\
\hline 4 & 3 & 3 & 2 & 3 & 2 \\
\hline 5 & 1 & 2 & 2 & 1 & 0 \\
\hline 6 & 4 & 6 & 2 & 3 & 2 \\
\hline 7 & 4 & 3 & 1 & 4 & 1 \\
\hline 8 & 5 & 6 & 2 & 6 & 4 \\
\hline 9 & 2 & 2 & 1 & 3 & 0 \\
\hline 10 & 6 & 4 & 1 & 3 & 1 \\
\hline 11 & 6 & 5 & 4 & 3 & 2 \\
\hline 12 & 5 & 4 & 3 & 4 & 3 \\
\hline 13 & 5 & 8 & 3 & 8 & 5 \\
\hline 14 & 5 & 5 & 2 & 6 & 4 \\
\hline 15 & 3 & 3 & 3 & 2 & 3 \\
\hline 16 & 6 & 5 & 4 & 2 & 3 \\
\hline 17 & 5 & 8 & 3 & 10 & 3 \\
\hline 18 & 4 & 6 & 3 & 7 & 1 \\
\hline 19 & 3 & 3 & 2 & 2 & 0 \\
\hline 20 & 5 & 6 & 2 & 3 & 2 \\
\hline 21 & 6 & 7 & 3 & 5 & 1 \\
\hline 22 & 3 & 2 & 3 & 3 & 2 \\
\hline 23 & 7 & 4 & 3 & 5 & 4 \\
\hline 24 & 6 & 5 & 3 & 8 & 2 \\
\hline 25 & 0 & 3 & 1 & 4 & 1 \\
\hline 26 & 3 & 8 & 4 & 6 & 4 \\
\hline 27 & 1 & 5 & 1 & 6 & 3 \\
\hline 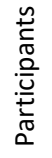 & 17 & 8 & 5 & 5 & 6 \\
\hline
\end{tabular}

Table 4: Results of critical Points of Development Questionnaire (Goussakovski 2000) 
Critical Points of development Questionnaire Table 4 shows the results of Critical Points of Development Questionnaire. This questionnaire contains five sections, with one for each developmental stage. However the numbers of questions for each section vary, as shown in the table. We therefore opted to mark as significant those where participants had scored above $50 \%$ of the possible responses. For these, it can see that 17 participants scored above this level for Stage 1: 0-6 months, followed by 8 who did so for Stage 2: 6 months-3 years. For older stages, numbers of participants were lower.

However, we also checked the results for all stages on the same score - in that we took 4 as just over $50 \%$ on 2 scales and used that same number of responses for all stages. When this is applied, Stages 1 and 2 both have 17 participants, with 15 participants likewise for Stage 4: 6-12 years. Stages 3 and 6 remain unchanged, with 5 and 6 participants respectively scoring above 4

\section{Brief Script Questionnaire}

We used the Brief Script Questionnaire as the basis for clinical interviews. On inspection, it seems likely that the results obtained may have been influenced by the nature of the interviews and/or the behaviour of the interview; with hindsight some alternative assessment methods was required for correlation.

Functional Ego States: results are shown in Table 5 and Figure 1. We found that Adapted Child and Critical Parent were about equal $(41 \%$ and $38 \%$ respectively) with much lower evidence for Free Child and Adult, and no evidence at all for Nurturing Parent.

Life positions: results are shown in Table 6 and Figure 2. It was found that 'I'm Not Ok, You're Not Ok" predominated $(62 \%)$

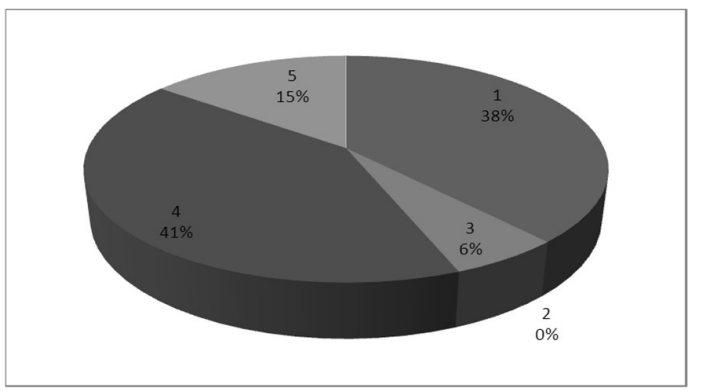

1 - Critical parent ego-state, 2 - Nurturing parent ego-state, 3 - Adult ego-state 4 - Adaptive child ego-state, 5 - Free child ego-state.

Figure 1. Distribution of dominant functional egostates of studied patients with paranoid form of schizophrenia.
Doors to therapy: results are shown in Table 7. For this, we used the first question in the Brief Script Questionnaire to diagnose one main open door. This resulted in $85 \%$ with behaviour as open door, with very low numbers for thinking and feeling.

Strokes: results are shown in Table 8. For this, questions $3 \mathrm{a}$ to $4 \mathrm{~b}$ in the Brief Script Questionnaire were used. It can be seen that more negative strokes were reported, for both physical and verbal form of strokes.

\begin{tabular}{|c|c|c|c|c|c|}
\hline & 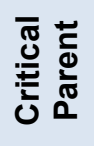 & 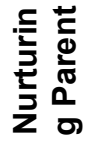 & $\frac{\text { 늘 }}{\frac{7}{4}}$ & 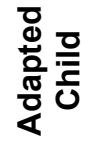 & ఖ 은 \\
\hline 1 & 1 & & & 1 & \\
\hline 2 & 1 & & & 1 & \\
\hline 3 & 1 & & & 1 & \\
\hline 4 & 1 & & & & \\
\hline 5 & 1 & & 1 & 1 & \\
\hline 6 & 1 & & & 1 & \\
\hline 7 & 1 & & & & 1 \\
\hline 8 & & & & & 1 \\
\hline 9 & & & & 1 & \\
\hline 10 & 1 & & & 1 & \\
\hline 11 & & & & 1 & \\
\hline 12 & & & & 1 & 1 \\
\hline 13 & 1 & & & & \\
\hline 14 & 1 & & & 1 & \\
\hline 15 & & & & 1 & 1 \\
\hline 16 & & & & 1 & \\
\hline 17 & & & & 1 & \\
\hline 18 & 1 & & & & \\
\hline 19 & & & & 1 & \\
\hline 20 & & & & 1 & \\
\hline 21 & & & & 1 & \\
\hline 22 & 1 & & & & \\
\hline 23 & 1 & & & & \\
\hline 24 & 1 & & 1 & & \\
\hline 25 & & & & & 1 \\
\hline 26 & 1 & & & 1 & \\
\hline 27 & & & & 1 & \\
\hline 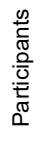 & 15 & 0 & 2 & 17 & 5 \\
\hline
\end{tabular}

Table 5: Results of Brief Script Questionnaire: Functional Ego States 


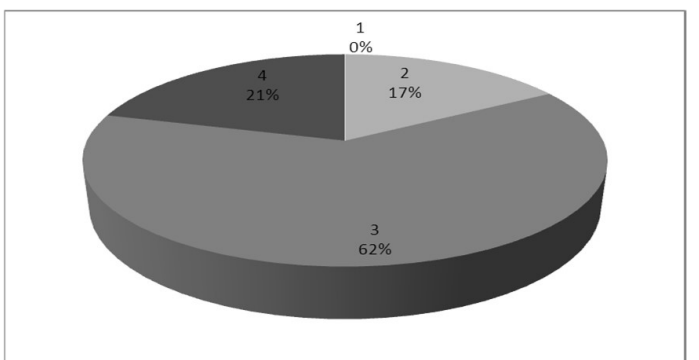

1 - "I'm - Ok, You - Ok", 2 - "I'm - Not Ok, You - Ok", 3 - "I'm - Not Ok, You - Not Ok", 4 - "I'm - Ok, You - Not Ok".

Figure 2. Typical life positions

\begin{tabular}{|c|c|c|c|c|}
\hline & $\begin{array}{l} \pm \\
\text { ㅁ } \\
\text { ㅇ } \\
\pm\end{array}$ & $\begin{array}{l}+ \\
\stackrel{0}{0} \\
\dot{\nu}\end{array}$ & $\begin{array}{l}\dot{1} \\
\dot{0} \\
亡\end{array}$ & 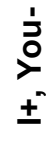 \\
\hline 1 & & & 1 & \\
\hline 2 & & & 1 & \\
\hline 3 & & 1 & & \\
\hline 4 & & & 1 & \\
\hline 5 & & 1 & 1 & \\
\hline 6 & & & 1 & \\
\hline 7 & & & 1 & 1 \\
\hline 8 & & & 1 & 1 \\
\hline 9 & & & 1 & \\
\hline 10 & & & 1 & \\
\hline 11 & & & & 1 \\
\hline 12 & & & 1 & \\
\hline 13 & & & 1 & \\
\hline 14 & & & & 1 \\
\hline 15 & & & 1 & \\
\hline 16 & & & 1 & \\
\hline 17 & & 1 & & \\
\hline 18 & & & 1 & \\
\hline 19 & & & & 1 \\
\hline 20 & & & 1 & \\
\hline 21 & & & & 1 \\
\hline 22 & & & 1 & 1 \\
\hline 23 & & & 1 & \\
\hline 24 & & & 1 & \\
\hline 25 & & & 1 & \\
\hline 26 & & 1 & 1 & \\
\hline 27 & & 1 & & \\
\hline 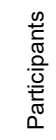 & 0 & 5 & 20 & 7 \\
\hline
\end{tabular}

Table 6: Results of Brief Script Questionnaire: Life Positions

\begin{tabular}{|c|c|c|c|}
\hline & 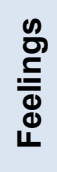 & 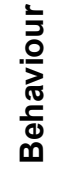 & 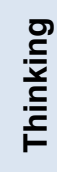 \\
\hline 1 & & 1 & \\
\hline 2 & & 1 & \\
\hline 3 & & 1 & \\
\hline 4 & & 1 & \\
\hline 5 & & 1 & \\
\hline 6 & & & 1 \\
\hline 7 & & 1 & \\
\hline 8 & 1 & & \\
\hline 9 & & 1 & \\
\hline 10 & & 1 & \\
\hline 11 & & 1 & \\
\hline 12 & & 1 & \\
\hline 13 & & 1 & \\
\hline 14 & & & 1 \\
\hline 15 & & 1 & \\
\hline 16 & & 1 & \\
\hline 17 & & & 1 \\
\hline 18 & & 1 & \\
\hline 19 & & 1 & \\
\hline 20 & & 1 & \\
\hline 21 & & 1 & \\
\hline 22 & & 1 & \\
\hline 23 & & 1 & \\
\hline 24 & & 1 & \\
\hline 25 & & 1 & \\
\hline 26 & & 1 & \\
\hline 27 & & 1 & \\
\hline 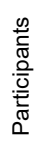 & 1 & 23 & 3 \\
\hline
\end{tabular}

Table 7: Results of Brief Script Questionnaire: Doors to Therapy

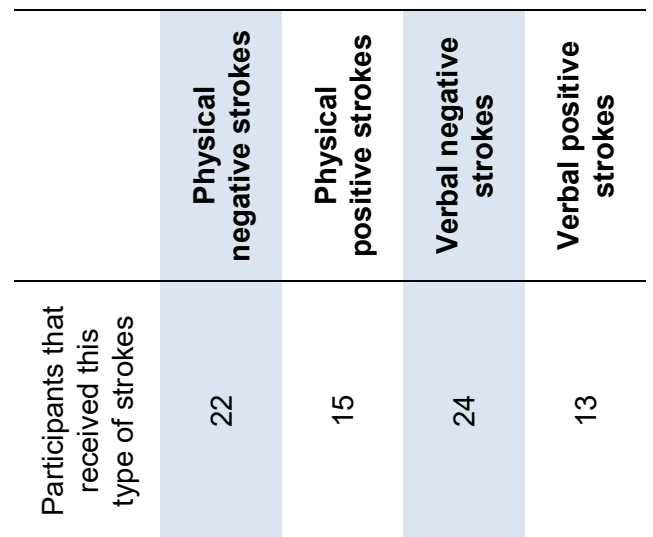

Table 8: Results of Brief Script Questionnaire: Strokes 


\section{Discussion}

\section{Ego States}

It can be seen that the Hay (2009) Internal Ego State Questionnaire completed by the participants showed several with high scores for Internal Parent and Internal Adult, and low scores for Internal Child. Hay's concept of internal ego states is similar to structural ego states, with her version of Internal Adult being presented as the equivalent of Berne's Adult ego state in the here-and-now. This would appear to confirm that, as taken into account under Ethical Considerations, participants were in remission and were capable of intellectual functioning.

The preponderance of Internal Parent and absence of Internal Child may be an indication that participants are very much influenced by what Hay describes as copies of parent figures during their childhood that they have somehow 'filed' and are still responding to, and which is maintaining an internal situation where they have repressed much of their natural child needs and experiences.

We can contrast this with the findings about Functional Ego States using the Stewart (1999) Brief Script Questionnaire, where Adapted Child and Critical Parent were more in evidence, with a notable lack of Nurturing Parent. The Parent results would seem to coincide with the high level of Internal Parent; consideration of the questions within the Brief Script Questionnaire show that participants were being invited to talk mostly about themselves and their childhood and might therefore be expected to be using Child or Parent rather than Adult as they recall past events. The Adapted Child seems the more likely, taking into account that the participants are already aware of having a mental health diagnosis and are likely to be recalling more of the negative and positive aspects of their childhood.

\section{Drivers}

There do not appear to be any significant patterns in the results from the Cox (2001) Driver Questionnaire. It may indeed be the case that those with a schizophrenic diagnosis are just as varied in terms of driver behaviour as the general public; however, this may also be a limitation of the questionnaire: for example, "being depended upon" in item 13 and "compare yourself with others" in item 17 might conceivably be selected by participants with any driver - the way in which they are dependent upon or compare themselves with others may be quite different.

Critical Points of Development

Using the calculation that identifies participants who scored four or more points on any of the questions, the pattern becomes that the most significant ages are 0-6 months, six months to 3 years, and at a slightly lower level, 6-12 years. Although the questionnaire uses different ages to those proposed by Levin (1982), the first two of these do relate to her Being (0-6 months) and Doing (6-18 months), and hence to early childhood experiences.

The other level relates to her Structure stage (6-12 years) when the young person is learning the skills they need to live out a script that they have adopted for themselves at the Identity stage (3-6 years).

Existential Life Positions and Strokes Bearing in mind that the participants have a diagnosis of schizophrenia and were receiving antipsychotic medications, it is hardly surprising that their life position appeared in most cases to be I'm not okay, You're not okay. These ties in with the way that they were able to identify more negative strokes than positive being given to them.

\section{Doors to therapy}

As shown in Table 7, there appeared to be a preponderance of participants that we identified as likely to have Behaviour as their open door (Ware 1983). Participants described themselves with words such as "active" or "passive", "slowly", "shy", "creative", "energetic", "independent", "strong", "ambitious", "sociable", "closed", etc. We assessed Thinking as the open door for self-descriptions such as "thoughtful", "analytic", "meditative", "intellectual", and "convinced". Our assessment of Feeling as the open door was based on expressions such as "emotional", "passionate", "impulsive", and "sad".

\section{Limitations}

A key limitation of this study is that the diagnostic methods were not validated in any way. They were not designed for research work but for practice; furthermore the Internal Ego State Questionnaire was actually designed by Hay (1996) for use by employees within an organisational rather than a clinical context. The Cox (2001) likewise includes a comment that it is not intended to be a personality test.

The questionnaires were also translated versions and this may have changed the meaning of the elements. The translations were already available in Russian; for future research more attention is needed to checking the accuracy of the translations.

Although larger than the previous TA-based studies referred to above, the sample size is still relatively small in that although the study continued for six months, out of approximately 50 patients who met the study criteria during that time, only 27 agreed to participate. This has therefore been a pilot study which we hope may stimulate further research by others. 
The diagnoses of schizophrenia were conducted by the hospital psychiatrists. They were unable to assure us that no subjects had concomitant mental illness, and the rules of confidentiality meant that they could not advise us who these might have been so we cannot be confident that the sample is representative.

Both collection and analysis of the data was conducted by the researcher, albeit under professional supervision. Hence the participants' responses may have been influenced by the researcher.

Finally, no attempt has yet been made to check the results for statistical validity, and no attempt has been made to investigate potential correlations between questionnaires and with the clinical interview. It is possible; therefore, that conflicting data generated by similar questions in different instruments remains unnoticed.

\section{Conclusion}

This study began with the intention to investigate the application of various transactional analysis concepts with a pilot group of participants who were hospitalised and diagnosed by psychiatrists as schizophrenia paranoid sub-type. As it progressed and the results were discussed with others, it became apparent that there were a number of limitations as described above. However, the decision has been taken to publish in order to present the methodology to others in the hope that this will stimulate further research.

Publication is also in line with IJTAR policy is to be open and transparent and publish any research, regardless of outcomes, and in line with Sterling's (1959) exhortation to pass on our learning to other researchers, and Popper's (1963) comment that every refutation should be regarded as a great success

\section{References}

Akyol, Ömer, Herken, Hasan, Uz, Efkan, Fadıllığlu, Ersin, Ünal, Süheyla, Söğüt, Sadık, Özyurt Hüseyin \& Asuman

Savaş, Haluk (2002) The indices of endogenous oxidative and antioxidative processes in plasma from schizophrenic patients: The possible role of oxidant/antioxidant imbalance Progress in Neuro-Psychopharmacology and Biological Psychiatry 26: 5 995-1005

American Psychiatric Association (1980). Diagnostic and statistical manual of mental disorders. (Third Edition): DSM-III. Washington, D.C.: American Psychiatric Association.

American Psychiatric Association. (2000). Diagnostic and statistical manual of mental disorders. (4th ed., text rev.). Washington, D.C.: American Psychiatric Association.
Bellack A. S., Turner S. M., Hersen M., Luber R.F. (1984) An examination of the efficacy of social skills trainig for chronic schizophrenic patients. Hosp. Comm. Psychiatry 35; 1023-1028.

Ben Othmen, Leila, Mechri, Anwar, Fendri, Chiraz, Bost, Muriel, Chazot, Guy, Gaha, Lotfi \& Kerkeni, Abdelhamid (2008) Altered antioxidant defense system in clinically stable patients with schizophrenia and their unaffected siblings Progress in Neuro-Psychopharmacology and Biological Psychiatry 32, 1, 1 155-159

Berlet, H.H., Bull, C., Himwich, H.E., Kohl, H., Matsumoto, K., Pscheidt, G R., Spaide, R., Tourlentes, T T. \& ValVerde, J M (1964) Endogenous Metabolic Factor in Schizophrenic Behaviour, Science 144 311-312.

Berne, E. (1961) Transactional analysis in psychotherapy: a systematic individual and social psychiatry. New York: Grove Press.

Berne, E. (1966) Principles of group treatment. New York: Grove Press.

Berne, E. (1988) Games People Play in Russian as People who play the game: the psychology of human destiny Gruzberg, A. (trans). Moscow: Progress Publishers.

Birchwood, M. \& Spencer E. (2005) Chapter in Schizophrenia V Ed. Edited by Maj M., Sartorius N. (trans.). Kiev: Spera.

Bradshaw, John (1991) Home Coming: Reclaiming and championing your inner child London: Piatkus Books

Cox, M. (1999). The relationship between ego state structure and function: a diagrammatic formulation. Transactional Analysis Journal, 29 (1). 49-58.

Cox, M. (2001). Driver questionnaire. Workshop Handout

Drury V., Birchwood M., Cochrane R. \& MacMillan F. (1996) Cognitive therapy and recovery from acute psychosis: a controlled trial. I. Impact on psychotic symptoms. Br. J. Psychiatry 169: 593-601.

Erskine, R.G. (2001). The schizoid process. Transactional Analysis Journal, 31 (1). 4-6.

Erskine, R.G., Hargaden, H., Jacobs, L., Little, R., O'Reilly-Knapp, M., Sills, C., Weil, T. \& Yontef, G. (2001). Withdrawal, connection, and therapeutic touch: a roundtable on the schizoid process. Transactional Analysis Journal, 31 (1). 24-32.

Garety P., Fowler D., Kuipers E., Freeman D., Dunn G., Bebbington P., Hadley C. \& Jones S. (1997) London-East Anglia randomized controlled trial of cognitive-behavioural therapy for psychosis. Br. J. Psychiatry 171: 420-426.

Garety P. A., Kuipers L., Fowler D., Chamberlain F. \& Dunn G. (1994) Cognitive behavioural therapy for drug resistant psychosis. Br. J. Med. Psychol. 67: 259-271. 
Goulding, M. \& Goulding, R (2000). Psychotherapy is a new solution: theory and practice in Russian. Moscow: Class Publishers.

Gusakovski, V.E. \& Palagin A.V. (2000). Psychological training "School Parents in Russian as Психологический тренине «Школа Родителей»:

http://goussakovski.narod.ru/articles/articl03.htm accessed 30 May 2014

Haimowitz, C. (2000). Maybe it's not 'Kick me' after all: transactional analysis and schizoid personality disorder. Transactional Analysis Journal, 30 (1). 84-90.

Hay, J. (1996). Transactional analysis for trainers. Sherwood: Sherwood Publishing.

Hogarty G.E., Anderson C.M., Reiss D.J., Kornbith S.J., Greenwald D.P., Jabna C.D. \& Medonia M.J. (1986)

Family psychoeducation, social skills trainig and maintence chemotherapy in the aftercare treatment of schizophrenia. One-year effacts of a controlled study on relapse and expressed emotion. Arch. Gen. Psychiatry 43: 633-642.

Hogarty G.E., Kornblith S.J., Greenwald D., DiBarry A. L., Cooley S., Urlich R. F., Carter M. \& Flesher S. (1997)

Three-year trials of Personal Therapy among schizophrenic patients living with or independent of family. Am. J. Psychiatry 154: 1504-1524.

Joines, V \& Stewart J. (1996). TA Today in Russian as Modern Transactional Analysis. St. Petersburg: SocioPsychological Centre.

Joines, V., Stewart, I. (2007) Personality Adaptations. A new Guide to Human Understanding in Psychotherapy and Counselling. Nottingham and Chapel Hill: Lifespace Publishing.

Levin, P. (1982). The cycle of development. Transactional Analysis Journal, 12 (2). 129-139.

Liberman R. P., Mueser K. T. \& Wallace C. J. (1986) Social skills training for schizophrenic individuals at risk of relapse. Am. J. Psychiatry 143: 523-526.

Little, R. (2001). Schizoid processes: working with the defenses of the withdrawn child ego state. Transactional Analysis Journal, 31 (1).

Mari J.L., Steiner D. (1998) Family intervention for schizophrenia. In Schizophrenia Module of the Cochrane Database of Systematic Reviews (EDS C.E. Adams, L. Duggan, K. Wahlbeck, P. White). Oxford: The Cochrane Collaboration

Perre, M \& Baumanna, U (Eds) (2007) Clinical Psychology. St. Petersburg: Peter Publishers.
Popper, K (1963) Conjectures and Refutations: The Growth of Scientific Knowledge London: Routledge

Pull, Charles (1999) Chapter 1: Diagnosis of Schizophrenia: A Review in Maj, Mario \& Sartorius, Norman (Eds) Chichester: John Wiley \& Sons 1-37.

Schiff, J.L., Erb,L.J, Warner, K., Schiff, S., Kline, D. \& Bowman, D. (1977). Biochemical evidence of cure in schizophrenics. Transactional Analysis Journal, 7 (2). 178181.

Schiff, J.L., Schiff A.W. (1971). Passivity. Transactional Analysis Journal, 1 (1). 71-78.

Steiner, K. (2003). Scripts People Live in Russian as Life scenarios of people Kliorina E. (trans). St. Petersburg: Peter Publishers.

Sterling, T (1959) Publication Decisions and their Possible Effects on Inferences Drawn from Tests of Significanceor Vice Versa. Journal of the American Statistical Association Vol 54 Iss 285 30-34

Stewart, I. (1999). Developing Transactional Analysis Counseling. London: Sage Publications

Tarrier N., Beckett R., Harwood S., Baker A., Yusupoff L. \& Ugarteburu, I. (1993) A trial of two cognitive-behavioural methods of treating drug-resistant residual psychotic symptoms in schizophrenic patients: I. Outcome. Br. J. Psychiatry 162: 524-532.

Tarrier, N., Yusopoff, I., Kinney, C., McCathy, E., Gladhill, A., Haddock, G. \& Morris, J (1998) Randomised controlled trial of intensive cognitive behaviour therapy for patients with chronic schizophrenia British Medical Journal 317 (7154) 303-307

University of Minnesota (1943) Minnesota Multiphasic Personality Inventory Minnesota: University of Minnesota Press

Ware, P. (1983). Personality adaptations (doors to therapy). Transactional Analysis Journal, 13 (1). 11-28.

Wilson, E.T., White, T.L. \& Heiber, R. (1985). Reparenting schizophrenic youth in a hospital setting. Transactional Analysis Journal, 15 (3). 211-215.

World Health Organization (2014a)

http://www.who.int/mental health/management/schizophre nia/en/ accessed 31 May 2014

World Health Organization (2014b)

http://www.who.int/mental health/resources/en/Gender dif ferences epid schizo references.pdf?ua=1 accessed 31 May 2014 


\section{Appendix 1: Internal Ego State Questionnaire (Hay 1996) (reproduced with permission)}

\section{Instructions}

For each statement, allocate a score to indicate how much it matches your own thinking.

not true for me $\quad 0$

moderately true for me

2

partly true for me

extremely true for me

3

Score

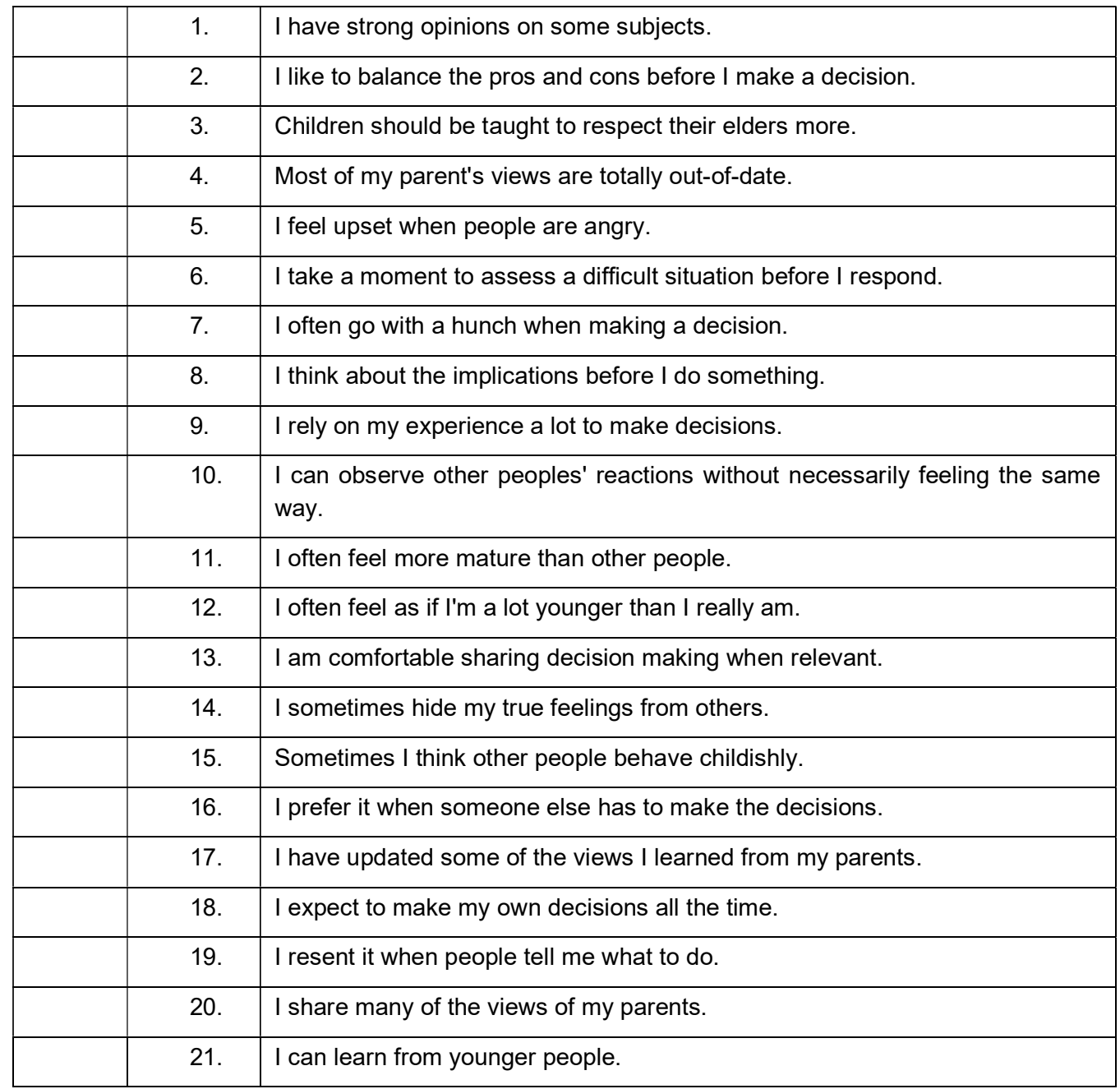


INTERNAL EGO STATE QUESTIONNAIRE - SCORING

Step 1. Transfer your scores to the summary below, against the question numbers, and add up each column.

1

3

9

11

15

18

20
2

6

8

10

13

17

21
4

5

7

12

14

16

19

TOTAL

$\begin{array}{lll}\text { Internal } & \text { Internal } & \text { Internal } \\ \text { Parent } & \text { Adult } & \text { Child }\end{array}$

Step 2. Draw a chart of your responses by marking horizontal lines at the score points for each ego state.

$21-$

$18-$

$15-$

$12-$

$9-$

$6-$

$3-$

0

$\begin{array}{lll}\text { Internal } & \text { Internal } & \text { Internal } \\ \text { Parent } & \text { Adult } & \text { Child }\end{array}$




\section{Appendix 2: Driver Questionnaire (Cox 2001) (reproduced with permission)}

'Drivers' are generalised messages about how to act that each of us acquires from family and social influences. The purpose of this questionnaire is to help you identify what kinds of 'driver' behaviour you typically get into, especially when under stress. The questions are formulated from general and clinical experience and are intended to stimulate self-awareness. This is not intended to be a 'personality' test.

ANSWER questions "yes" or "no" or "to some extent".

SCORING: see overleaf.

1. In general do you hide or control your feelings?

2. Are you reluctant to ask others for help?

3. Do you set yourself high standards and then criticise yourself for failing?

4. Do you do things (especially for others) that you don't really want to?

5. Do you have a tendency to do many things simultaneously?

6. Do you hate 'giving up' or 'giving in', hoping 'this time it will work'?

7. Is it important to you to be right?

8. Is it important to you to be liked?

9. Do you have a tendency to start things and not finish them?

10. Do you set unrealistic time limits (especially too short)?

11. Are you fairly easily persuaded?

12. Do you dislike being 'different'?

13. Do you have a tendency to be in a position of being depended upon?

14. Do you feel discomforted by small messes, mistakes, discrepancies?

15. Do you get impatient fairly easily?

16. Do you hate to be interrupted?

17. Do you tend to compare yourself with others?

18. Do you have a tendency when problem solving to 'go round in circles'?

19. Do you tend to 'keep going', not noticing hunger, tiredness, and other needs?

20. Do you often talk at the same time as others, or finish their sentences for them?

21. Do you generally explain things in detail and with precision?

22. Do you prefer to get on with a job rather than talk about it?

23. Do you prefer to do things on your own?

24. Do you dislike conflict, and tend to avoid it?

25. Do you have a tendency to be a rebel or be the 'odd one out'?

* The concept of 'driver' behaviour was developed by two transactional analysts, Kahler and Hedges [Capers] (TAJ 4.1 p.32), and written about by Mavis Klein in "Pain and Joy" (Boyars 1993). This questionnaire has been created based on the work of those authors, and due acknowledgement is given here. 


\section{SCORING FOR DRIVER QUESTIONNAIRE}

Collate your scores by giving yourself marks

'yes' = $1 \quad$ 'no' $=0 \quad$ 'to some extent' $=0.5$

Then draw up five groups of scores as follows:

$\begin{array}{ccccc}\text { column 1 } & \text { column 2 } & \text { column 3 } & \text { column 4 } & \text { column 5 } \\ \text { Q.3 } & \text { Q.4 } & \text { Q.5 } & \text { Q.1 } & \text { Q.6 } \\ 7 & 8 & 10 & 2 & 9 \\ 14 & 11 & 15 & 13 & 17 \\ 16 & 12 & 20 & 19 & 18 \\ 21 & 24 & 22 & 23 & 25\end{array}$

A maximum score of 5 could be obtained in each column. Where you have scored 3 or more in a column it would seem likely that this 'driver' behaviour is a significant tendency in you. The questions in each column are representative of one of five types of 'driver':

\section{Column $1 \quad$ BE PERFECT \\ Column 2 PLEASE OTHERS \\ Column 3 HURRY UP \\ Column 4 BE STRONG \\ Column 5 TRY HARD}

It is likely that people have one or two preferred driver patterns and that most people behave in a 'driven' way at least some of the time. Driven behaviour (compulsive patterned responses) is more likely under stress. Although there are five of these main 'drivers', the form in which the person acts in response to the message can be infinitely varied, for example some perfectionists pay more attention to tidiness, and some care more about cleanliness.

Sometimes a person scores very low on all the driver columns, or may even have scores of 0 . This may or may not signify, and it is important to remember that the purpose of this questionnaire is to stimulate self-reflection. It is not a personality test.

Mary Cox M.Ed

Clinical Teaching and Supervising Transactional Analyst

Questionnaire revised 1999 


\section{Appendix 3: Critical Points of Development Questionnaire (Goussakovski 2000 based on Bradshaw 1991 via Patricia J Cox) (reproduced with permission)}

Answer the following questions. After you read the question, stop and listen to your feelings. Answer "yes" or "no" to each question.

Stage from birth to 6 months:

Do you have or have you had in the past a tendency to overeat, abuse alcohol or take drugs?

Does it ever happen that you are not confident in your ability to meet your needs?

Do you find it hard to believe in other people, so that all the time you need to control them?

Do you ignore the physical needs of the body, such as eating when not hungry or not realising how tired you

are?

Do you ignore your needs for good nutrition and exercise?

Do you visit the doctor and the dentist only in extreme cases?

Do you feel a deep fear that you will be left? Do you feel now or ever felt despair when a love affair came to an end?

Stage from 6 months to 3 years:

Is it difficult for you to determine what you want?

Are you afraid to know, when you get to a new place?

In complex situations, do you not know whether you want to have something?

Are you overly anxious (worry over nothing)?

Do you often have conflicts with the authorities?

Are you doing everything possible to avoid conflict?

Do you feel guilty when someone refuses?

Are you often overly critical of people?

When you reach success, is it difficult for you enjoy or believe in your achievements?

Stage 3 to 6 years

Do you have difficulties in communicating with relatives (husband, wife, children, boss, and friends)?

Are you in control of your feelings in most cases?

Is it difficult for you to express your feelings?

Do you believe that you are responsible for the behaviour and feelings of others? (For example, do you feel that you can annoy or offend people?)

Do you often accept obscure or contradictory information without asking for clarification?

Do you feel responsible for the problems of marriage or divorce of your parents?

Stage 6 to 12 years:

How often do you compare yourself with others and find yourself worse than others?

Would you like to have more friends of both sexes?

Do you often feel uncomfortable in society?

Do you feel uncomfortable in a group?

Do you often have conflicts occur with your employees? Members of your family?

Are you proud of how strictly and accurately you follow laws?

How often do you say what you want to do?

Is it difficult for you to finish the job?

Are you afraid that you can make a mistake? Do you feel humiliated when you are forced to admit mistakes?

Do you often get angry or criticize others?

Do you spend a lot of time to reflect and analyse what someone told you?

Do you believe that everything you do, is not well done? 
Stage 12 to 18 years:

Are you often are in conflict with the authorities (authorities, police and other officials)?

Do you get into a rage about the meaninglessness of the rules and orders that other people take for granted?

When you come to visit your parents, do you feel in the role of an obedient (or rebellious) child?

Are you a dreamer, preferring to read novels or science fiction, but not active in life?

Do people sometimes say that it is time you grew up?

Do you find that it very difficult to express your opinion when it is contrary to generally accepted standards?

Do you speak a lot about the great deeds that you want to implement in the future and that you will never fulfil?

\section{PROCESSING OF THE RESULTS}

Count the number of affirmative answers for each section. If it is at least half the total number of questions on the relevant section, the possible origins of your problems lie in this age. 


\section{Appendix 4: Brief Script Questionnaire (Stewart, 1999) (reproduced with permission)}

1. What kind of person are you.

2a. Give five words to describe your mother.

2b. Give five words to describe your father.

3a. When you were a child, and your mother was angry at you, what would you have been doing?

3b. When you were a child, and your father was angry at you, what would you have been doing?

4a. When you were a child, and your mother was pleased with you, what would you have been doing?

4b. When you were a child, and your father was pleased with you, what would you have been doing?

$5 \mathrm{a}$ If your mother were to write her autobiography, and you had to find a title for it, what would that title be?

5b. If your father were to write his autobiography, and you had to find a title for it, what would that title be?

6a. In your family, is any story told about your birth?

6b. Have you ever thought you might kill yourself?

6c. Have you ever thought you might kill anyone else?

7. Have you ever thought you might go crazy?

8. What will it say on your tombstone?

9. When things go wrong for you, how do you usually feel?

10. If you keep on the way you are at the moment, where are you going to be five years from now?

11. If you were given magic wishes, how or what would you change? 